\title{
A BIOLOGICAL INTERPRETATION OF MORAL SYSTEMS
}

\author{
by Richard D. Alexander
}

\begin{abstract}
Moral systems are described as systems of indirect reciprocity, existing because of histories of conflicts of interest and arising as outcomes of the complexity of social interactions in groups of long-lived individuals with varying conflicts and confluences of interest and indefinitely iterated social interactions. Although morality is commonly defined as involving justice for all people, or consistency in the social treatment of all humans, it may have arisen for immoral reasons, as a force leading to cohesiveness within human groups but specifically excluding and directed against other human groups with different interests.
\end{abstract}

A moral system is essentially a society with rules. Rules are agreements about what is permitted and what is not, about what rewards and punishments are likely for specific acts, about what is right and wrong. The definition of rules can be variously expanded or restricted. If it is used so as to include only consciously understood, deliberately applied rules, then moral systems may be uniquely human. This may also be the case if certain kinds of unconscious or nonconscious elements are allowed into the definition. I will leave this problem for now, only noting that it is my intent here to concentrate on moral systems as they are known or discussed with respect to humans.

Aside from its reference to values, the concept of morality implies altruism or self-sacrifice. Not all moral acts call for self-sacrifice, however, and not all self-serving acts, by any means, would be termed immoral. On the other hand, I suspect most would agree that a moral

Richard D. Alexander is the Donald Ward Tinkle Professor of evolutionary biology and curator of insects, Museum of Zoology and Division of Biological Sciences, University of Michigan, Ann Arbor, Michigan 48109. He presented this paper at a symposium on "The Function and Management of Aggression and Cooperation in Biocultural Evolution," sponsored by the Institute on Religion in an Age of Science at the annual meeting of the American Association for the Advancement of Science in Detroit, Michigan, 26-31 May 1983. Parts of this paper have been included in his book manuscript, The Biology of Moral Systems. He says, "I thank the following people for commenting on the manuscript: Laura Betzig, Warren G. Holmes, Gordon L. Kane, Bobbi S. Low, Gene Mesher, Paul W. Sherman, Rrbert Smuts, and Richard Wrangham."

[Zygon, vol. 20, no. 1 (March 1985).]

(C) 1985 by the Joint Publication Board of Zygon. ISSN 0044-5614 
life will inevitably call for some acts with net cost to the actor. Similarly, many acts with a net value to the actor would be judged immoral because alternative courses of action of value to others are available at the time but are not taken. Generally speaking, then, immoral is a label we apply to certain kinds of acts by which we help ourselves or hurt others, while acts that hurt ourselves or help others are more likely to be judged moral than immoral. As virtually endless arguments in the philosophical literature attest, it is not easy to be more precise in defining morality per se.

Agreement seems to be universal (and consistent with the above remarks) that moral (and ethical) questions and problems arise because of conflicts of interest; I have never found an author who disagrees. If there were no conflicts of interest among people and societies it is difficult to see how concepts of right and wrong, ethics and morality, and selfishness and altruism could ever have arisen. Probably, society would have remained simple in structure, and nothing like humans would ever have evolved.

Few people would deny that most or all humans tend to behave selfishly on occasion-indeed, in ways that would almost universally be termed immoral. This being true, it is difficult to apply the adjectives moral and immoral to human individuals let alone whole societies (hence, the moral philosophers' problem of "duality" in human nature); rather, these terms seem most appropriately applied to individual acts. Moreover, there is the complication that morality within groups (patriotism, loyalty, group effort) often, at least, correlates with opposite kinds of behavior to members of other groups, thus raising the question whether cooperation-to-compete has been the historical function of group unity. If it has, then we are faced with the possibility that morality was invented or instituted (and maintained and elaborated) for reasons that in a modern or intellectually consistent discussion would necessarily be seen as immoral. This is true unless the members of other groups can successfully be judged subhuman or nonhuman-a telling point in view of depictions of enemies during wartime and the widespread tendency of peoples to call themselves by names meaning human or the people.

The general idea of morality as serving others, or at least taking account of their interests rather than concentrating wholly on one's own, seems to be responsible for the generation of models of idealized moral conditions, or societies within which all people treat the interests of all people as equal in importance. These models, which prevail in the modern literature of moral philosophy, represent hypothetical societies in which conflicts of interest have been erased or supplanted by a concern for the welfare of all people in the society or for (in the utilitarian concept) the "greatest good to the greatest number." Pre- 
sumably, the culmination of putting such a model into practice-or the true ideal of morality-would be a world in which all people everywhere viewed as equally important the interests of all people everywhere.

Probably, nearly everyone would accept the improbability of achieving an idealized morality involving universal indiscriminate altruism. On the other hand, many people might support the idea of striving to realize an idealized morality while accepting its improbability. Many would regard it as immoral deliberately to abandon such a goal.

The paradoxes inherent in these propositions have preoccupied philosophers and, indeed, people in all walks of life throughout history. In some sense they are the most important questions humans can ponder, if for no other reason than that we tend to draw into the moral and ethical realm every social problem that assumes increasing significance-notably the international arms race, exploitation and pollution of environments, medical uses of technology, population growth, racism, sexism, pornography, drug use, and many others. All together such issues account for virtually all major news stories, attesting to the centrality of conflicts of interest in our lives.

The difficulties in understanding the network of paradoxes that seems to make up the structure of moral and ethical propositions and practices, and the apparent incompatibility of morality as self-sacrifice with a history of evolution by natural selection, have caused even biologist-philosophers to base their conclusions, or appeal to readers, on grounds other than biological information and arguments, or to declare that trends toward morality are contrary to evolution and that biological knowledge cannot explain moral behavior (e.g., Huxley 1898; Lack 1954; Dobzhansky 1967).

I think that evolutionary subtheories in biology developed in the past twenty-six years (Fisher 1958; Williams 1957, 1966a, 1966b; Hamilton 1964; Trivers 1971, 1974; Alexander 1979) place us in a new situation, in which we can start to resolve the age-old paradoxes surrounding the concepts of morality and ethics and in which modern views of idealized moralities can be accounted for. What follows here is an effort to show that morality need not be contrary to natural selection or inconsistent with it but that, at least as practiced and perhaps also as imagined by most, it may instead be a logical outgrowth or extension of the practice of social reciprocity by a complexly social organism which changes as a result of both genetic evolution and cumulative social learning. ${ }^{1}$

\section{INTERESTS}

Leaving aside the question of conscious belief or personal opinion about one's goals or intentions, there is every reason to accept that humans, like other organisms, are so evolved that their "interests" are 
reproductive. Said differently, the interests of an individual human (i.e., the directions of its striving) are expected to be toward ensuring the indefinite survival of its genes and their copies, whether these are resident in the individual, its descendants, or its collateral relatives.

In today's novelty-filled environments, human activities may often be directed in ways that do not in fact lead to increased success in reproduction or the perpetuation of one's own genes. Moreover, people aware of their background in evolution may be able to use conscious reflection and deliberate decisions to live their lives contrary to, or irrespective of, whatever their evolutionary background has prepared them to be. Neither of these possibilities, however, affects the essential certainty that humans have evolved to maximize survival of their genes through reproduction.

We need not be concerned with the possible argument that interests are only definable in terms of what people consciously believe are their interests or intentions. Biologists continually investigate the life interests of nonhuman organisms while lacking knowledge on this point, and nonhuman organisms live out their lives serving their interests without knowing in the human sense what those interests are. Moreover, it is axiomatic that we are not consciously aware of all that motivates us, and that consciousness (hence, at least to some extent which parts of our knowledge and attitudes are conscious and which parts are not) could not have evolved if it did not serve reproductive interests.

\section{CONFLiCTS OF INTERESTS}

Recognizing that interests are reproductive provides us with the means for understanding and quantifying their conflicts. The first step is realizing that, for several well-described and documented reasons, selection is usually most effective at low levels in the hierarchy of organization of life (Fisher 1958; Williams 1966a; Lewontin 1970; Dawkins 1976, 1982; Alexander and Borgia 1978; Alexander 1979; Leigh 1983). One consequence is that individuals may be expected to behave so as to serve their own (genetic, reproductive) interests rather than the interests of others or of the whole group whenever the interests of others or the group conflict with those of the individual.

The second step, in recognizing and quantifying conflicts of interest, is to realize that an evolutionary history of genetic individuality, which is a consequence of sexual reproduction, ought to yield individuals evolved to judge partial overlaps of interest with other individuals through, first, proximate mechanisms that correlate with numbers and kinds of genealogical links and, second, opportunities to achieve goals or deflect threats by cooperative efforts with others. 
Several facts support the hypothesis that conflicts of interests arise out of a history of genetic individuality. First, there are evidently no reports of conflict among genetically identical individuals within clones among species that have for a long time reproduced asexually; and evidence of extraordinary cooperativeness in such cases abounds (cf. Alexander, in prep.). Second, altruism appears generally to diminish with decreasing degrees of relatedness in sexual species wherever it is studied, in humans as well as nonhuman species. Third, in cases in which identity or near-identity of genetic interests is achieved in sexual species (without genetic identity per se) cooperation is also dramatic. Examples are the two partners in lifetime monogamy and the members of the large social insect colonies that are actually nuclear families of enormous size (e.g., honeybees, ants, termites). In each case the cooperating parties (spouses, or workers and queens) reproduce via the same third parties (offspring, or siblings and offspring) to which they are more or less equally related genetically and which are usually the closest (needy) relatives available to each of them (Hamilton 1964; West Eberhard 1975; Alexander in prep.).

\section{Life EFFort and Social Interactions}

The recent development of evolutionary subtheories about senescence, life patterns, reproductive value, and the costs and benefits of different kinds of social interactions enables us to begin constructing a general theory or picture of the components of human social life, the reproductive significance of these components, and how they interrelate.

Figure 1 describes a hypothetical human lifetime in terms of some ideas from modern evolutionary biology. The lifetime is postulated to be made up of effort, defined as expenditure of calories and taking of risks in the interests of reproducing (actually, in the interests of carrying out the best effort to cause one's genes to be immortal) (Williams 1966a). ${ }^{2}$

Theoretically, effort can be defined entirely in terms of calories. This would require measuring wasted calories, which is probably most difficult in cases of premature death as a result of risk-taking. One would have to calculate lifetime availabilities of calories and the amount of reproduction per lifetime, then subtract the proportion of calories already used by the deceased individual to reproduce effectively. To my knowledge no one has yet incorporated such difficult calculations into a specific use of the concept of effort, but risk must still be taken into account in quantifying effort.

Lifetimes can be divided into somatic effort and reproductive effort. Somatic effort is designed (by evolution) to lead to growth, development, 
and maintenance of the soma, always, presumably, in such ways as to maximize effectiveness of later reproductive effort. Somatic effort, then, amounts to the accumulation and conversion of resources in the interests of reproduction. Somatic effort typifies what is commonly termed the juvenile stages, although as maintenance it obviously has to occur in adults expecting to reproduce repeatedly or across a long period. Juvenile stages evidently evolve solely because, as amassers of resources, they raise the peak of reproductive value (achieved at about the usual age of first reproduction-see fig. 1) sufficiently to more than offset the expenses of mortality and lengthened generation time that are inevitably associated with the juvenile stage (cf. Low and Alexander, in prep.).
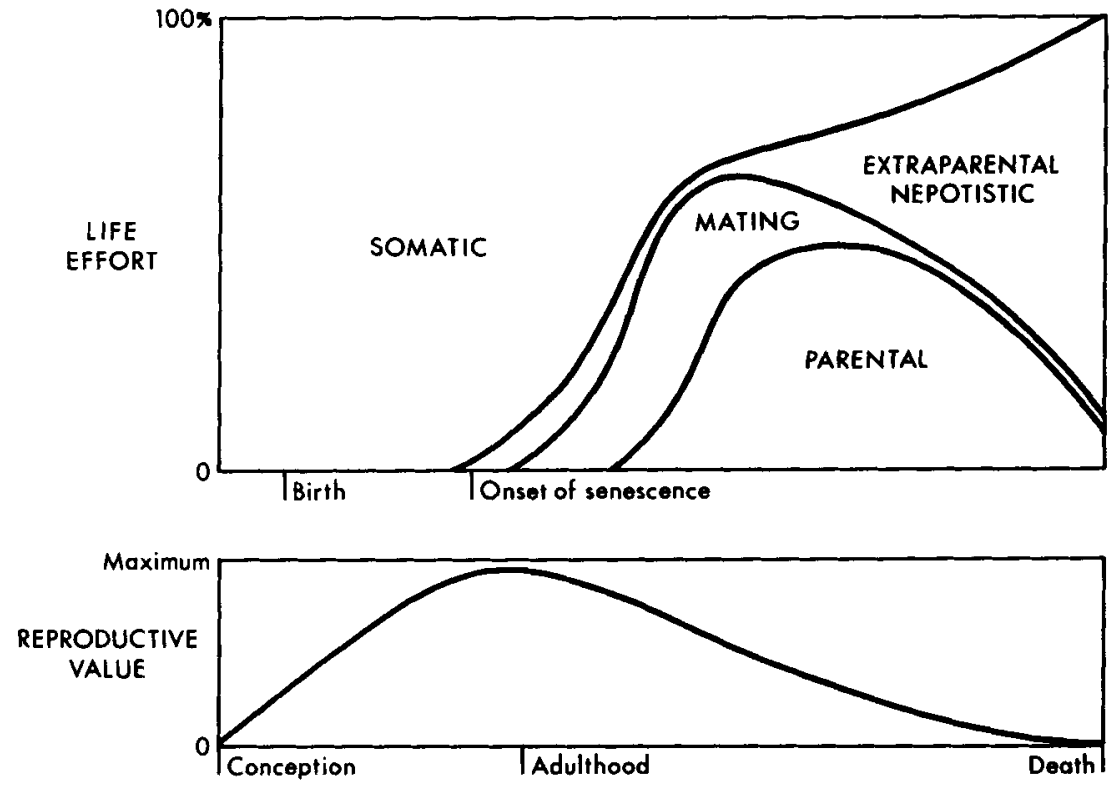

FIG. 1.-A hypothetical human lifetime, showing a plausible distribution of different kinds of effort and changes in reproductive value. All early effort is somatic, and somatic effort continues until death. Reproductive effort onsets before adulthood, here postulated in the form of extraparental nepotistic effort (e.g., help, or yielding of resources, to siblings). Senescence onsets shortly afterward, when the effect of reproductive effort becomes sufficient to reduce residual reproductive value. Mating and parental effort onset later, and each of the three forms of reproductive effort are postulated to maximize at different times during adult life.

Reproductive effort, unlike somatic effort, lowers residual reproductive value, and for this reason its usual age of onset is predicted to correspond to the usual age of onset of senescence (defined as increasing susceptibility to environmental insults) (Williams 1957, 1966a). Re- 
productive effort includes mating effort (on behalf of gametes), parental effort (on behalf of offspring), and extraparental nepotistic effort (on behalf of collateral relatives and descendants other than offspring) (Low 1978; Alexander and Borgia 1978). Theoretically, senescence can be caused to onset from any of these kinds of effort.

Because of male-female differences in early investment in the zygote, leading in turn to differences in investment in gametes before zygote formation, some acts by one sex (e.g., males) may represent mating effort for them (and be judged selfish) while the consequences of the acts (e.g., gifts or other resources) may represent (or be converted to) parental effort by the other sex (the female, in this case). The use of such resources by females to contribute to the reproductive value of prezygotic eggs, moreover, may be regarded as altruistic, because of the eventual usefulness of the resources to the zygote, which of course contains genetic materials from the male (Alexander and Borgia 1979). In all these cases the involved effort is reproductively (or genetically) selfish even if phenotypically costly or altruistic (Hamilton 1964; Alexander 1974).

Somatic effort can be further analyzed by dividing it into direct and indirect forms (see fig. 2). Direct somatic effort is that engaged in by an individual with direct effects upon its own survival or well-being-for example, eating, drinking, fleeing a predator, or taking shelter from a storm-without help from anyone. Indirect somatic effort is that involving assistance from others (efforts to secure resources for relatives through such interaction would be termed indirect nepotistic effort). Indirect somatic effort thus always involves investments in reciprocity, although the nature of such investments may vary considerably, as between, say, a nursing infant and its mother as compared to two partners in a business venture. It is contended here that investments in social reciprocity evolve (or the proximate mechanisms by which they are effected evolve) so as to yield returns greater than their expenses, that is, they always represent indirect somatic or indirect nepotistic effort. Such acts would therefore be judged not altruistic but (when indirect somatic effort) both phenotypically and genetically selfish or (when indirect nepotistic effort) phenotypically altruistic but genetically selfish.

Reciprocity can be direct or indirect, and immediate or delayed. Direct recipracity occurs when an individual's social contribution or investment (positive or negative) is returned (not necessarily in the same currency) by the same individual in which the original actor invested. Indirect reciprocity $I$ have defined as those cases in which the dividends from social investments are likely to come from individuals other than those helped (or hurt) by the original actor (Alexander 1977, 1979). ${ }^{3}$ 
I think these considerations bring us closer to taking the vagueness out of the concept of morality and tend to reinforce the theory that, in biological terms, the social life of humans is composed of nepotismone-way flows of benefits to relatives in which the return is genetic (Hamilton 1964)-and reciprocity-two-way or still more complex flows of benefits involving both relatives and nonrelatives (Trivers 1971; Axelrod and Hamilton 1981).

\begin{tabular}{|c|c|c|}
\hline \multirow[b]{2}{*}{ KIND OF EFFORT } & \multicolumn{2}{|c|}{ EFFECTS } \\
\hline & PHENOTYPICALLY & GENETICALLY \\
\hline \multicolumn{3}{|l|}{ SOMATIC EFFORT } \\
\hline $\begin{array}{l}\text { DIRECT } \\
\text { Immediate } \\
\text { Delayed }\end{array}$ & selfish & selfish \\
\hline $\begin{array}{l}\text { INDIRECT } \\
\text { (Involves } \\
\text { Reciprocity, s. lat.) }\end{array}$ & selfish & selfish \\
\hline $\begin{array}{l}\text { Direct Reciprocity } \\
\text { Immediate } \\
\text { Delayed }\end{array}$ & & \\
\hline $\begin{array}{l}\text { Indirect Reciprocity } \\
\text { Immediate } \\
\text { Delayed }\end{array}$ & & \\
\hline \multicolumn{3}{|c|}{$\begin{array}{l}\text { REPRODUCTIVE EFFORT } \\
\text { (= Nepotism, s. lat.) }\end{array}$} \\
\hline Mating Effort & altruistic & selfish \\
\hline $\begin{array}{l}\text { Parental Effort } \\
\text { Extraparental } \\
\text { Nepotistic Effort }\end{array}$ & $\begin{array}{l}\text { altruistic } \\
\text { altruistic }\end{array}$ & $\begin{array}{l}\text { selfish } \\
\text { selfish }\end{array}$ \\
\hline
\end{tabular}

Fig. 2.-Kinds of effort and their outcomes. Direct somatic effort refers to self-help that involves no other persons. Indirect somatic effort involves reciprocity, which may be direct or indirect. Returns from direct or indirect reciprocity may be immediate or delayed. Reciprocity can be indirect for two different reasons, or in two different ways. First, returns (payment) for a social investment (positive or negative) can come from someone other than the recipient of the investment, and second, returns can go either to the original investor or to a relative or friend of the original investor.

The essence of moral systems seems to lie in patterns of indirect reciprocity (Alexander 1977, 1979, in prep.), and so I will now concentrate on describing such patterns and their results, while acknowledging and attempting to explain how nepotism and direct reciprocity may influence the development and maintenance of indirect reciprocity. 
Indirect reciprocity is what happens when direct reciprocity occurs in the presence of an interested audience. Some of its consequences are described in figures 3, 4, and 5 . These consequences include the concomitant spread of altruism (as genetically valuable social investment), rules, and cheating. I am not contending that cost-benefit analyses of the kind depicted in figures 3,4 , and 5 are always carried out deliberately or consciously but only that they do occur, sometimes consciously sometimes not, and that we are evolved to be exceedingly accurate and quick at making such analyses.

\section{INDIRECT RECIPROCITY}

REWARDS (WHY ALTRUISM SPREADS)

1. A helps $B$

2. B helps (or overhelps) $A$

3. C, observing, helps $B$, expecting that

4. B will also help (or overhelp) $\mathrm{C}$ (etc.)

or

1. A helps $B$

2. $B$ does not help $A$

3. C, observing, does not help B expecting that, if he does

4. B will not return the help

(etc.)

Fig. 3.-Indirect reciprocity: why altruism spreads.

\section{INDIRECT RECIPROCITY}

PUNISHMENT (WHY RULES SPREAD)

1. A hurts $B$

2. $C$, observing, punishes $A$ expecting that, if he does not,

3. A will also hurt $C$ or that

4. someone else, also observing, will hurt $\mathrm{C}$, expecting no cost (etc.)

FIG. 4.--Indirect reciprocity: why cheating spreads. 


\section{INDIRECT RECIPROCITY}

DECEPTION (WHY CHEATING SPREADS)

1. $A_{1}$ makes it look as though he helps $B$

2. $C_{1}$ helps $A_{1}$, expecting that $A_{1}$ will also help him

3. $C_{2}$ observes more keenly and detects $A_{1}$ 's cheating and does not help him (avoids or punishes him)

4. $A_{2}$, better at cheating, fools $C_{2}$

5. $C_{3}$ detects $A_{2}$ 's cheating (etc.)

$\left.\begin{array}{l}C_{1} \rightarrow C_{2} \rightarrow C_{3} \\ A_{1} \rightarrow A_{2} \rightarrow A_{3}\end{array}\right\}$ either learning or evolution (or both)

FIG. 5.-Indirect reciprocity: why punishment spreads.

The long-term existence of complex patterns of indirect reciprocity may be seen as favoring the evolution of keen abilities, first, to make one's self seem more altruistic than is the case and, second, to influence others to be altruistic in such fashions as to be deleterious to themselves and beneficial to the moralizer, for example, to lead others to invest too much, invest wrongly in the moralizer or his relatives and friends, or invest indiscriminately on a larger scale than would otherwise be the case. Thus, individuals are expected to parade the ideas of much altruism and of indiscriminate altruism as beneficial, so as to encourage people in general to engage in increasing amounts of social investment whether or not it is beneficial to their interests. They may be expected to locate and exploit avenues of genetic relatedness leading to nepotistic flows of benefits (e.g., to insinuate themselves deceptively into the role of relative or reciprocator so as to receive the benefits therefrom). They may also be expected to depress the fitness of competitors by identifying them, deceptively or not, as reciprocity cheaters; to internalize rules or evolve the ability to acquire a conscience, which I have interpreted as the ability to use our own judgment to serve our own interests; and to self-deceive and display false sincerity as defenses against detection of cheating and attributions of deliberateness in cheating (Trivers 1971; Campbell 1975; Alexander 1974, 1977, 1979, 1982, in prep.).

\section{Moral Behavior as Self-Beneficial}

If current views of evolutionary processes are correct, reciprocity will flourish when the benefits donated by each partner are relatively 
inexpensive compared to the returns (Trivers 1971, West Eberhard 1975). This kind of asymmetry is prevalent under two circumstances: the first is when threats or promises extrinsic to the interactants cause joint similar efforts to be worth more than the sum of their separate contributions, leading to more or less symmetrical cooperation. The second is when the contributions of partners in reciprocity are different, leading to division of labor. The second situation can arise out of different abilities or training in different contributors, or from differences in their accumulated resources.

Indirect reciprocity must have arisen out of the search for interactants and situations by which to maximize returns from asymmetrical, hence highly profitable social reciprocity. One consequence of large, complex societies in which reciprocity is the principal social cement and indirect reciprocity is prevalent is that opportunities for such mutually profitable asymmetrical reciprocal interactions are vastly multiplied. This situation in turn fosters the appearance of tendencies to engage in indiscriminate social investment (or indiscriminate altruism)-willingness to risk relatively small expenses in certain kinds of social donations to whomever may be needy-because of the prevalence and keenness of observation and the use of such acts by others to identify individuals appropriate for later reciprocal interactions. ${ }^{4}$ In complex social systems with much reciprocity, being judged as attractive for such possibilities may become an essential ingredient for success. Similarly, to be judged harshly because of failure to deliver small social benefits indiscriminately in appropriate situations may lead to formidable disadvantages because of either direct penalties or lost opportunities in subsequent reciprocal interactions.

Figure 6 describes hypothetical social stages through which the evolving human species might have passed (many times). These seem to lead toward a utilitarian or idealized model of morality in which all social investment becomes indiscriminate altruism (but, as argued here, have so far invariably fallen short).

Direct reciprocity must have occurred early in the human line as a part of the male-female interaction. Initially it may have functioned as mating effort, subsequently as indirect nepotism through effects on offspring produced jointly by the pair. Alternatively, direct reciprocity may have arisen as a modification of nepotistic altruism. I suggest that indirect reciprocity followed quickly from one (or all) of these beginnings, leading to the evolution of ever keener abilities to observe and interpret situations with moral overtones. In such a milieu, I would argue, a modicum of indiscriminate altruism would arise as social investment, because of benefits to individuals of being viewed as altruists. 


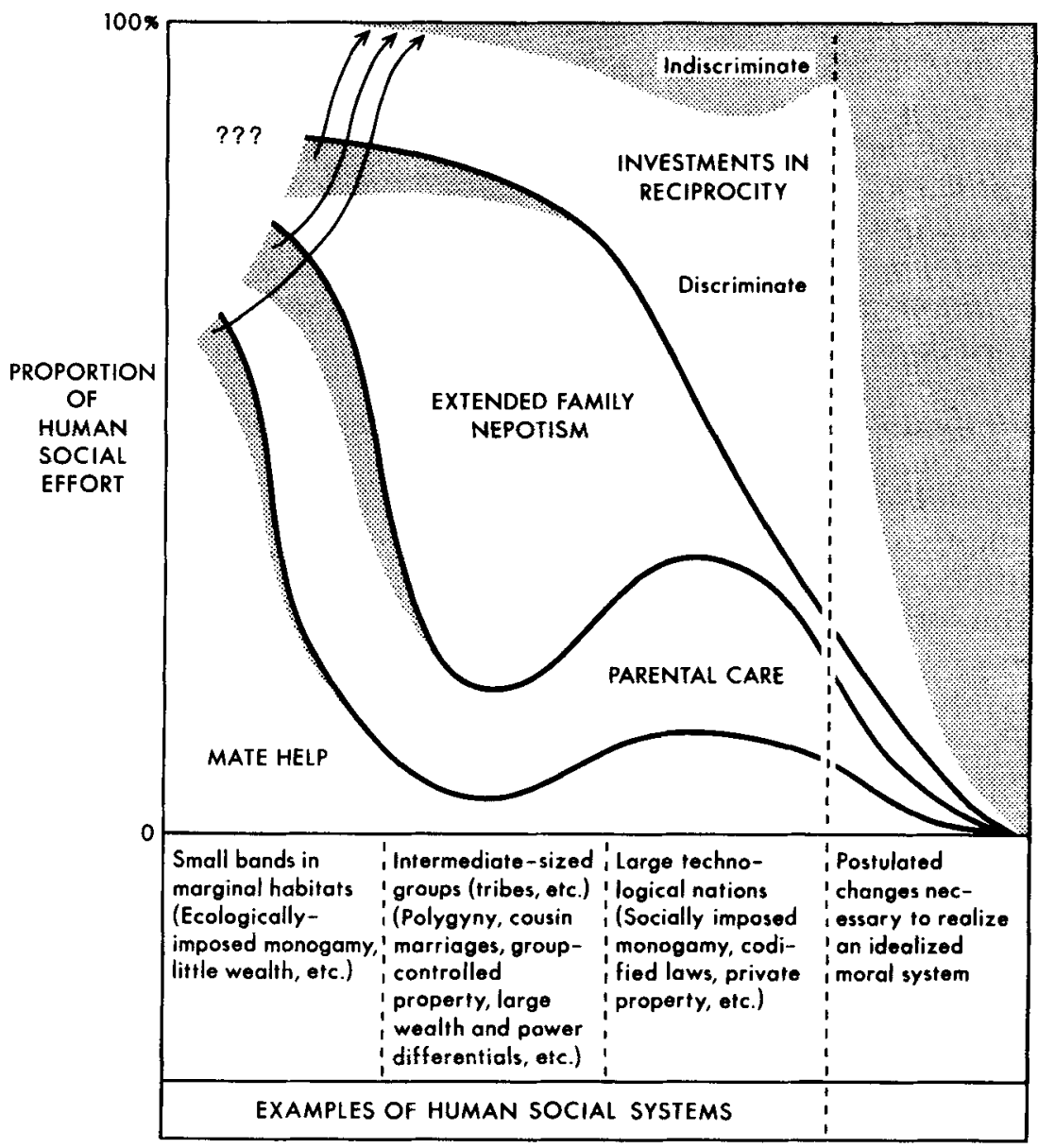

Fic. 6.-A speculation about the relative importance of different kinds of social interactions in some different kinds of societies. The principal purpose is to show the probable origins of indiscriminate altruism, its probable significance in different societies, and the changes from existing societies that would be necessary to realize an idealized model of morality in which everyone was indiscriminately altruistic.

General encouragement of indiscriminate altruism and general acceptance of its beneficial effects result in a society with high social unity. This encouragement and acceptance is expected to occur partly because of the likelihood, much of the time, that nearly everyone benefits from living in a unified society and partly because individuals gain from inducing indiscriminate altruism in others (and from inducing degrees of it that are deleterious to those others). I would postulate that self-serving indiscriminate social investment-because it was seen as net-cost altruism and was interpreted wrongly as part of a real trend 
toward universal indiscriminate (net-cost) altruism-provided the impetus for the idealized modern model of morality portrayed in figure 6 .

It is a crucial part of the argument that indiscriminate altruism seems to have been viewed widely not as a beneficial social investment to the altruist but as self-sacrificial or net-cost altruism (i.e., as both phenotypically and genetically altruistic). In turn, morality in general was viewed as self-sacrificing, and it seemed logical to project the expansion of indiscriminate, self-sacrificial altruism to include most or all social interactions-thus providing, perhaps, part of the reason for the idealized moral models of many modern thinkers which call for utilitarianism based on a self-sacrificing kind of indiscriminate altruism (cf. Alexander in prep.).

The concepts of justice as fairness, or equal opportunities for all, and of justice and equality as moral must have gained currency during human history in relation, first, to the suppression of widespread nepotistic favoritism and, second, to the expansion of a base of indiscriminate altruism; both changes seem to have occurred as reciprocity, rather than nepotism, became the principal social cement of increasingly large and complex human societies (cf., Alexander 1979). These trends must have contributed to the rise of universal indiscriminate altruism as an ideal of morality and a rational social objective. I find it an easy speculation that the concept of a single just God for all people bears a close relationship to the same trend. If followed to its logical consequences (a goal evidently not yet achieved), this concept disallows ethnocentrism, political and national chauvinism, and other forms of cooperation-to-compete that may have characterized the course of human history, even perhaps providing its central driving force, and that sometimes also characterize the practice of religion.

It would seem that societies become more close-knit and congenial environments as the base of self-serving indiscriminate social investment expands to include a higher proportion and a broader diversity of social activities. Within small bands of close relatives such investment will necessarily be largely nepotistic in its effects. In large technological societies this cannot be true; there expansion of indiscriminate social investment must be fueled by the complexity and effectiveness of indirect reciprocity. Such expansion seems obviously more likely to occur when the nature and immediacy of external threats favor high levels of cooperativeness, when within-group opportunities are expanding so as to yield a broadening base of profitable opportunities from both cooperation and division of labor, and when accountability for one's acts (including rewards for evidence of altruistic tendencies) is high. By the same argument, indiscriminate social 
investment is expected to diminish in urban or other situations involving high geographic mobility, low likelihood of repetitive interactions, and other circumstances that, in effect, create societies of strangers within which individuals are neither stigmatized for failures to invest socially nor rewarded for providing such investments readily. Indiscriminate social investment also seems less likely to expand in societies with contracting economies (as opposed to expanding economies in which everyone seems to be gaining, even if some gain more than others), societies in which social mobility is excessively restricted (new coalitions will not be sought if they have no function), and societies that lack external threats.

It is a novel aspect of the view of society presented here that it can explain in evolutionary terms, first, human morality as practiced, second, society's view of itself and of morality as seemingly contrary to evolutionary history, and, third, the existence of idealized moral models that are clearly unlikely in evolutionary or any other terms. It also justifies indiscriminate altruism as a model worth pursuing, but without necessarily calling for the regular existence or practice of genetically deleterious forms of altruism (or, in modern environments, altruism based on proximate responses appropriate to such effects). In other words, morality and moral systems, moralizing, self-deceit, conscience, and a host of other human traits and tendencies now appear explainable only in light of our history of evolution by natural selection, rather than being paradoxical both in evolutionary terms and to those not concerned with biological arguments. The key lies in the argument that systems of indirect reciprocity cause some (indeterminate and adjustable) amounts of indiscriminate altruism to be reproductively favorable to the altruist or to relate to peoples' proximate feelings and attitudes as if this were the case, and that misinterpretation of this indiscriminate altruism as costly, rather than as social investment likely to be profitable to the investor, has been responsible for a widespread if not universal misinterpretation of what it means to be moral. ${ }^{5}$

\section{World Peace?}

The most serious moral or conflict-of-interest problem in the world today is surely the international arms race. Efforts to resolve it seem to reduce to two diametrically opposed alternatives. The first is a kind of nasty, unfettered mutual deterrence about which one can scarcely be optimistic over the long run (perhaps even the short run, e.g., Rothschild 1983). The second is one or another brand of what I call universal brotherhood, which scarcely any thoughtful person can see as realistic because the models involved call for an uninhibited willingness to self-sacrifice. The prevalence of this second approach, in con- 
nection with this most serious of all world problems, seems to me sufficient to demonstrate that the idealized indiscriminate altruism I have been discussing here is by no means a straw man (e.g., Schell 1982; Singer 1981). ${ }^{6}$

We have not so far been presented with a social model that moves us toward a kind of universal brotherhood that is explicitly based on individually self-serving behavior or that caters to the usual proximate mechanisms of such behavior. The view of moral systems given here suggests that, perhaps with a considerable amount of creative imagination, such models may be developed.

I am hypothesizing, then, that part of the key to approaching the increasingly urgent human goal of world peace and world harmony (conditions heretofore unrealized in the living world, human or otherwise) lies in the kind of self-understanding, discussed here, that comes from biological knowledge. In 1971 I suggested that arguments or facts appealing to selfish motivations, rather than exhortations to serve humanity, are most likely to solve the problem of rising population levels. This prediction has probably been borne out (Ehrlich and Ehrlich 1979; Alexander in prep.); lowered rates of population growth seem to have come about because of such factors as declining economies, rigid and sometimes extreme governmental penalties for large families, the pill as a route to the good life, and the social stigmatizing of large families. ${ }^{7}$

In lieu of universal deep understanding of evolution and its cumulative effects on human nature (such deep understanding being evidently a condition not likely to be realized in the foreseeable future), the goal of world peace, unfortunately, may also be achievable only-or most likely-through routes that also appeal widely to the traits and tendencies elaborated through the human history of evolution by natural selection.

\section{NOTES}

1. I do not use the adjective biological in the title of this essay to mean genetic, physiological, or hard-wired as it is used almost universally by human-oriented scholars outside biology. Biology is the science of life, and I deplore the misleading and erroneous dichotomy that opposes "biological" to "cultural" or "learned." Because of it, every time a biologist stands up to speak on human behavior he is saddled with the accusation of genetic determinism and expected to speak only about some kind of at least extremely rare behavior that cannot be modified adaptively by the varying and somewhat predictable circumstances of life. No evolutionary theory or subtheory worthy of consideration excludes environmentally adjustable behaviors. It is a fiction to suppose that evolution by natural selection does not produce traits that change predictably and adaptively to meet changing circumstances. Epigenesis is universal, phenotypes are universal, and the function of epigenesis and of phenotypes is to allow adjustment to local and temporary conditions. As one example, the differences among the worker, soldier, and queen castes of termites and ants (involving morphology, physiology, behavior, life length, senescence pattern, etc.) are determined solely by environmental variations. No one supposes for a 
moment that this means that the potential and tendency for these variations to occur when they do did not evolve.

2. Theoretically, effort can be defined entirely in terms of calories. This would require measuring wasted calories, which is probably most difficult in cases of premature death as a result of risk-taking. One would have to calculate lifetime availabilities of calories and the amount of reproduction per lifetime, then subtract the proportion of calories already used by the deceased individual to reproduce effectively. To my knowledge no one has yet incorporated such difficult calculations into a specific use of the concept of effort, but the concept of risk must still be taken into account.

3. Trivers (1971) referred to this as pect of sociality as "generalized reciprocity." For reasons unknown to me I missed this designation when I initiated the phrase "indirect reciprocity." I do recall that I avoided the term "generalized reciprocity" explicitly because of the way Sahlins (1965) had used it (cf. Alexander 1979). Sahlins typified generalized reciprocity as involving one-way flows of benefits in which the expectation of return is vague or nonexistent. He included nepotism, citing the case of a mother nursing her child, and with respect to nonrelatives seemed to be referring to what we would now call genetic or reproductive altruism. Perhaps both terms will survive: indirect reciprocity for cases in which the return explicitly comes from someone other than the recipient of the original beneficence and generalized reciprocity for social systems in which indirect reciprocity has become complex and general.

4. I do not mean to imply that aid will be given regardless of the likely net cost or benefit; indeed, my arguments indicate that this is not likely to happen. The implication of "indiscriminate" is rather that the aid will be given, regardless of the identity of the individual to whom it is given. Even this is obviously an oversimplification, since it is likely that some kinds of aid will be given only to close relatives, some only to relatives and friends, some to strangers only if there is evidence of reciprocating ability, some to strangers only when friends or associates will know, etc. Nevertheless, I think that we all regard it as important to be convinced that there are some kinds of aid-giving that our associates will give to any person, regardless of identity or other variables. Many contributions to charity are of just this sort.

5. Charles Darwin developed an evolutionary theory of morality different from that presented here (and highly sexist!), which is summarized in the following words: "Ultimately our moral sense or conscience becomes a highly complex sentiment-originating in the social instincts, largely guided by the approbation of our fellow-men, ruled by self-reason, and confirmed by instruction and habit. It must not be forgotten that although a high standard of morality gives but a slight or no advantage to each individual man and his children over the other men of the same tribe, yet that an increase in the number of well-endowed men and advancement in the standard of morality will certainly give an immense advantage to one tribe over another. A tribe including many members who, from possessing in a high degree the spirit of patriotism, fidelity, obedience, courage, and sympathy, were always ready to aid one another, and to sacrifice themselves for the common good, would be victorious over most other tribes; and this would be natural selection. At all times throughout the world tribes have supplanted other tribes; and as morality is one important element in their success, the standard of morality and the number of well-endowed men will thus everywhere tend to rise and increase" (Darwin 1871, 500).

This is a group selection model, and not an unreasonable one. Darwin is not entirely clear in his arguments, however, as is suggested by his phrases (above) "slight or no advantage" and "largely guided by approbation of our fellow-men [and]... selfinterest..." He notes that "It is obvious, that the members of the same tribe would approve of conduct which appeared to them to be for the general good, and would reprobate that which appeared evil. To do good unto others-to do unto others as ye would they should do unto you-is the foundation-stone of morality. It is, therefore, hardly possible to exaggerate the importance during rude times of the love of praise and the dread of blame. A man who was not impelled by any deep, instinctive feeling, to sacrifice his life for the good of others, yet was roused to such actions by a sense of glory, would by his example excite the same wish for glory in other men, and would strengthen by exercise the noble feeling of admiration. He might thus do far more good to his tribe 
than by begetting offspring with a tendency to inherit his own high character" (Darwin 1871, 500).

Darwin sometimes gives the impression that he sees the "approbation and disapprobation" of "fellow-men" as a manipulative device that turns what would otherwise be selfish acts into expensive ones or altruistic acts into self-interested ones. But he does not ever clarify this point and frequently says something that indicates the opposite: "Finally the social instincts, which no doubt were acquired by man as by the lower animals for the good of the community, will from the first have given to him some wish to aid his fellows, some feeling of sympathy, and have compelled him to regard their approbation and disapprobation" (Darwin 1871, 493). Accordingly, I think we must give authorship of the idea that "heroism" is reproductive to Fisher: "The mere fact that the prosperity of the group is at stake makes the sacrifice of individual lives occasionally advantageous, though this, I believe, is a minor consideration compared with the enormous advantage conferred by the prestige of the hero upon all his kinsmen" (Fisher J1930] 1958, 265). Fisher at once shows that the group and individual level selection arguments are not entirely incompatible (both may be operative), while supporting the latter as of greater importance. His theory is, in general, the same as that I am presenting here.

Huxley states similarly: "So far as it [the ethical process] tends to make any human society more efficient in the struggle for existence with the state of nature, or with other societies, it works in harmonious contrast with the cosmic process [natural selection]. But it is none the less true that, since law and morals are restraints upon the struggle for existence between men in society, the ethical process is in opposition to the principle of the cosmic process, and tends to the suppression of the qualities best fitted for success in that struggle" (Huxley 1898, 31). Here and elsewhere Huxley does not make it clear that showing moral tendencies is in fact a quality essential for reproductive success when one's environment is a closely knit society of humans.

Huxley's understanding, however, is more complete than many who quote him imply. Thus, he says that "the practice of that which is ethically best-what we call goodness or virtue-involves a course of conduct which, in all respects is opposed to that which Jeads to success in the cosmic struggle for existence" (Huxley 1898, 81-82). "Let us understand, once for all, that the ethical progress of society depends, not on imitating the cosmic process, still less in running away from it, but in combating it" (Huxley 1898, 83). But he footnotes the first of these quotes as follows: "Of course, strictly speaking, social life, and the ethical process in virtue of which it advances toward perfection, are part and parcel of the general process of evolution, just as the gregarious habit of innumerable plants and animals, which has been of immense advantage to them, is so. A hive of bees is an organic polity, a society in which the part played by each member is determined by organic necessities. ... Even in these rudimentary forms of society, love and fear come into play, and enforce a greater or less renunciation of self-will. To this extent the general cosmic process begins to be checked by a rudimentary ethical process, which is, st rictly speaking, part of the former, just as the 'governor' in a steam-engine is part of the mechanism of the engine."

6. It seems possible to me that social changes in some technological societies during the past few centuries, in the direction of egalitarianism with respect to opportunity (e.g., universal suffrage, civil rights, affirmative action, and similar phenomena), have actually influenced moral philosophy significantly, causing much more attention to what I am here calling the idealized model of indiscriminate altruism.

7. One caveat: It is a virtue of the deliberate pursuit of an idealized model of indiscriminate altruism that no one can afford to lag too far behind the behavior of the most altruistic or of the majority when most are altruistic. But this virtue, as I am seeing it, disappears when such pursuits become mired in we-they exclusions contradictory to the model.

\section{REFERENCES}

Alexander, R. D. 1971. "The Search for an Evolutionary Philosophy of Man." Proceedings of the Royal Society of Victoria. Melboume 84:99-120.

. 1974. "The Evolution of Social Behavior." Annual Review of Ecology and Systematics 5:325-83. 
1977. "Natural Selection and the Analysis of Human Sociality." In Changing Scenes in the Natural Sciences, 1776-1976, ed. C. E. Goulden, 283-337. Special Publication 12, Philadelphia Academy of Natural Sciences.

1979. Darwinism and Human Affairs. Seattle: Univ. of Washington Press.

1982. "Biology and the Moral Paradoxes." Journal of Social and Biological Structures 5:389-95.

(in prep.). The Biology of Moral Systems.

Alexander, R. D. and Gerald Borgia. 1978. "Group Selection, Altruism, and the Levels of Organization of Life." Annual Review of Ecology and Systematics 9:449-74.

. 1979. "On the Origin and Basis of the Male-Female Phenomenon." In Sexual Selection and Reproduction Competition in Insects, ed. M. F. and N. Blum, 417-40. New York: Academic Press.

Axelrod, R. and W. D. Hamilton. 1981. "The Evolution of Cooperation" Science 211:1390-96.

Campbell, D. T. 1975. "On the Conflicts Between Biological and Social Evolution and Between Psychology and Moral Tradition." American Psychologist 206:139-48.

Darwin, Charles. 1871. The Descent of Man and Selection in Relation to Sex. New York: Appleton.

Dawkins, R. 1976. The Selfish Gene. New York: Oxford Univ. Press. 1982. The Extended Phenotype. Oxford \& San Francisco: W. H. Freeman.

Dobzhansky, T. 1967. The Biology of Ultimate Concern. New York: New American Library.

Ehrlich, P. R. and A. H. Ehrlich. 1979. "What Happened to the Population Bomb?" Human Nature 2:88-92.

Fisher, R. A. [1930] 1958. The Genetical Theory of Natural Selection. 2d ed. New York: Dover.

Hamilton, W. D. 1964. "The Genetical Evolution of Social Behaviour, I, II." Joumal of Theoretical Biology 7:1-52.

Huxley, T. H. 1898. Evolution and Ethics and Other Essays. New York: Appleton.

Lack, D. 1954. The Natural Regulation of Animal Numbers. New York: Oxford Univ. Press.

1957. Evolutionary Theory and Christian Belief. London: Methuen.

Leigh, E. G. 1983. "When Does the Good of the Group Override the Advantage of the Individual?" Proceedings of the National Academy of Science 80:2985-89.

Lewontin, R. C. 1970. "The Units of Selection." Annual Review of Ecology and Systematics $1: 1-18$

Low, B. S. 1978. "Environmental Uncertainty and the Parental Strategies of Marsupials and Placentals." American Naturalist 112:197-213.

Low, B. S. and R. D. Alexander. (in prep.). "Evolutionary Theory and Studies of Child Development."

Rothschild, E. 1983. "Review of Defense Department Annual Report to Congress Fiscal Year 1984." New York Review of Books, April 14, 30:40-50.

Sahlins, M. D. 1965. "On the Sociology of Primitive Exchange." In The Relevance of Models for Social Anthropology, ed. M. Banton, 139-236. London: Tavistock.

Schell, J. 1982. "Reflections (Nuclear Arms, Part III): The Fate of the Earth." New Yorker, February 15, 45-107.

Singer, P. 1981. The Expanding Circle. New York: Farrar, Straus \& Giroux.

Trivers, R. L. 1971. “The Evolution of Reciprocal Altruism." Quarterly Review of Biology $46: 35-57$.

1974. "Parent-Offspring Conflict." American Zoologist 14:249-64.

West Eberhard, M. J. 1975. "The Evolution of Social Behavior by Kin Selection." Quarterly Review of Biology 50:1-33.

Williams, G. C. 1957. "Pleiotropy, Natural Selection, and the Evolution of Senescence." Evolution 11:398-411.

1966a. "Natural Selection, the Costs of Reproduction, and a Refinement of Lack's Principle." American Naturalist 100:687-90. Press.

1966b. Adaptation and Natural Selection. Princeton, N.J.: Princeton Univ. 